\title{
A Context-Aware Architecture for Improving Collaboration of Users in Groupware Systems
}

\author{
Luis G. Montané-Jiménez, Edgard Benítez-Guerrero and Carmen Mezura-Godoy \\ Facultad de Estadística e Informática, \\ Universidad Veracruzana, Xalapa, Mexico 91020 \\ Email:1montane@uv.mx,edbenitez@uv.mx,cmezura@uv.mx
}

\begin{abstract}
A Context-Aware Groupware System (CAGS) enables the members of a team to communicate, cooperate and coordinate their activities to achieve a common goal, by providing them tools that are aware of their current execution context and adapt accordingly. CAGS can be found in several domains such as entertainment, particularly Collaborative First-PersonShooter (FPS) video games. In CAGS, the means of collaboration traditionally provided to users (e.g. text and audio messaging) are not necessarily adequate: for instance, in a FPS, messages can distract the gamer due to the speed of the game. This paper reports a study that, for Collaborative FPS, identifies advantages/disadvantages of current means of collaboration and social behaviors that arise when players interact face-to-face or remotely. Based on this study, a context-aware conceptual model and architecture is proposed for CAGS aimed to improve user collaboration.
\end{abstract}

Keywords-Computer-Supported Cooperative Work, Groupware, Communication Means, Context-Aware, Video Games

\section{INTRODUCTION}

A Groupware System (GS) enables the members of a team to communicate, cooperate and coordinate their activities in order to achieve a common goal, in a loosely-coupled manner, by using a combination of mobile and fixed technologies. With advances on wireless networks and the emergence of new electronic devices (e.g. tablets, smart phones) the demand for GS has increased, causing these tools to become an essential element in several application domains, such as commerce, health, business, and entertainment. It is in this last domain where we are witnessing the proliferation of On-Line MultiPlayer Video Games (particularly those of type First-Person Shooter - FPS), where players of a team collaborate to beat other teams.

Traditional GS provide their users with information and services in predetermined ways: the same data items are presented in the same way to all the users, and the same services are invoked in the same sequence. Although this behavior is enough for some applications, a GS should satisfy more efficiently the information/services needs of its users. A GS can be enhanced if the context of its users is considered in the execution of activities, in order to provide adequate and relevant data and/or services; i.e. it is context-aware. Context variables related to a single user have been traditionally used in context-aware groupware systems (CAGS); for instance, in a FPS video game, contextual data of relevance for a player can be his/her energy level, the number of available munitions, and his/her current virtual location. However, context variables related to social aspects have been less studied. Awareness, defined as an understanding of the activities of others [1], is a classical concept that has been explored in CAGS; for instance, a player of a FPS video game can know the current virtual location of his/her teammates, and make decisions based on that knowledge. Another relevant concept, Social Presence (SP), defined as the degree of relevance of the other person in performing an interaction [2], is also being investigated.

Now, the means of collaboration traditionally offered by current CAGS, particularly FPS videogames (e.g. text and audio messaging) at first sight seem limited. For instance, sending messages requires the user to deviate his/her attention from the game, which can affect his/her performance. It is then necessary to analyze the traditional means of collaboration offered in CAGS, particularly in Video Games of type First-PersonShooter, in order to identify elements and conditions necessary to improve them. This paper presents a review of the main aspects related to Context-Aware Groupware Systems, and report an exploratory study considering as case study a Video Game of type FPS, which identifies advantages/disadvantages of current means of collaboration. Based on the findings of the exploratory study, a conceptual model and an architecture for CAGS is proposed.

The remainder of this paper is organized as follows. Section II introduces Context-Aware Groupware Systems and describes the trends in Context-Aware Collaborative Video Game Systems. Section III describes the exploratory study and Section IV defines the context-aware conceptual model and architecture for improving users collaboration. Finally, Section $\mathrm{V}$ presents a summary and introduces future works.

\section{Context-Aware Groupware Systems And Video GAMES}

\section{A. Context-Awareness and Groupware}

Context-Aware Computing focuses on the creation of systems that use context to provide relevant information and/or services to the user, where relevancy depends on the user's task [3]. Let us note that there is no consensual definition of context: Dey [3] defines it as "any information that can be used to characterize the situation of an entity. An entity is a person, place or object that is considered relevant to the interaction between a user and an application, including the user and applications themselves", while Chen [4] defines it as "the set of states and values of the environment that either determine the behavior of an application or in which an application event happens and is of interest to the user". 
Nowadays, most of the work related to modeling, management and use of context are intended for systems that do not support collaborative work. These works have traditionally considered context variables such as temperature, time, location, and even the physical activity of the user (e.g. running, walking). However, social context variables (roles, social rules, state of the group activity group, state of other users) have been not considered in detail. Therefore, it is relevant to explore the use of contextual information in collaborative activities in order to provide tools and mechanisms for making the collaborative process more efficient.

It is possible to define a Context-Aware Groupware System (CAGS) as software that enables the members of a team to communicate, cooperate and coordinate their activities in order to achieve a common goal by providing tools which are sensitive to any information that can enhance collaboration. These tools acquire, manage and use context information produced by individual and group activities (in the form of user preferences, states of activities, physical/virtual locations, and sequences of activities, for instance) in order to support users to achieve their common goals more effectively and efficiently than in a traditional Groupware System.

Building a CAGS is a challenging task, as it requires considering the traditional aspects of software development (requirements analysis, design, implementation, and evaluation), but also it is necessary to consider the aspects related to the incorporation of context awareness: modeling, acquisition and use of context. With respect to models, some proposals are activity-centered (e.g. [5], [6], [7], [8]), while others are user-centered (e.g. [9], [10], [11], [12]). For instance, [13] presents a model for context-aware mobile collaborative systems based on the notions of user and group spaces, and where users execute activities within a working group or either in isolation respectively, under a certain context. Let us note that most models do not allow dynamic changes in the rules and conditions that impact the performance of users in a collaborative activity; however, in real world scenarios these variables tend to constantly change. Thus, models considering dynamic changes in protocols and social rules defined and adapted by end users are needed. With respect to development tools, one can find (a) architectures (e.g. [14], [15], [16]), (b) middlewares (e.g. [17], [18], [19], [20]), and (c) frameworks (e.g. [21], [22], [23], [24]).

\section{B. Context-Aware Collaborative Video Games}

Current Collaborative Video Games can be considered as basic context-aware systems, as they already use information about the performance of their users (points scored or game levels completed) in order to re-adapt the game to offer a more attractive user experience (changing dynamically the difficulty level, for instance). This can be fun but it is limited, as it has already been noticed by researchers whose works are aimed to take collaborative games to the next level. [25] presents a qualitative study to discuss the impact of awareness tools in Quake (a FPS Video Game), while [26] shows that the users play better when they use awareness tools. Other related works are [27] which presents an analysis for improving communication tools through the use of user and group information, [28] which presents a method to design games that support collaborative

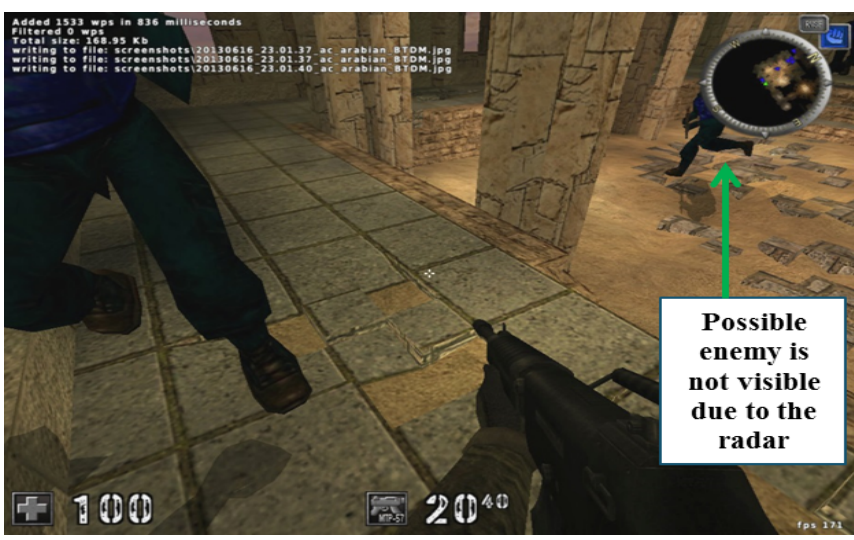

Figure 1. Video Game screen. It presents energy level, bonuses, score, munitions.

learning, and [29] which presents a study aimed to analyze collaborative activities performed by students and teachers in a game-based learning environment. So, it is desirable to propose mechanisms to change the behavior of the game depending on the current social context.

The aforementioned works are important because they represent the first efforts aimed to have context-aware collaborative video games. However, they are limited:

- User preferences about the Graphical User Interface (GUI) are not considered, so the same GUI is presented to all the players. This can have a negative effect in the performance of a player (for instance a player can get easily distracted when messages are displayed at the upper part of the screen instead of at the bottom part), so user preferences need to be taken into account (see Fig. 1).

- Those works consider only awareness as the social aspect (for instance, reporting the presence of nearby enemies in radar); however social aspects are much more than just awareness and, for this reason, it seems attractive to propose models considering roles, group rules, goals, unusual behaviors, objects manipulated, social protocols, types of communication (e.g. visual, physical), actions (e.g. write, speak, etc.) to enable the representation of complex situations.

- It is not clear if the traditional means of collaboration (e.g. voice/text messaging) are sufficient or appropriate to meet the needs of users in a distributed setting. It seems then interesting to investigate if the information generated when players are face-to-face and lost when they are geographically distributed can be detected and used in alternative means of collaboration.

- The speed and efficiency to collaborate and communicate information in a FPS Video Game are important and need to be considered, otherwise there is a high possibility that the players cannot generate a strategy and then can be easily beaten. Thus, solutions to this issue need to be proposed.

The study presented in Section III was conducted to explore and analyze these issues. 


\section{EXPLORATORY STUDY}

An exploratory and analytical experiment was designed in order to identify whether there are additional elements that traditional means of collaboration do not consider. The following describes the materials and methods used to perform the experiment, and finally we discussed the obtained results.

\section{A. Experimental design}

For this study, two different experiments were designed and executed. In the first experiment $\left(e_{1}\right)$ a group of players were divided in two teams of equal size, and they played a FPS game in a face-to-face setting: they were in the same classroom and each player knew who were their teammates. For the second experiment $\left(e_{2}\right)$, players were also divided in two teams of equal size, but this time they played in different physical location (e.g. homes, schools, etc.). The intention of defining $e_{1}$ and $e_{2}$ was to detect behaviors that give us indications of the existence of other variables that arise from a face-to-face interaction between players and these variables are not covered by traditional tools offered in the game (e.g. messages, audio messages predefined). The $e_{2}$ was performed in a different day than the $e_{1}$.

The first experiment $e_{1}$ was conducted with 8 players, all of them students, $25 \%$ are women and $75 \%$ are men, all between 19 and 26 years old and with at least one year of experience in playing FPS video games. The second experiment $e_{2}$ was performed with 8 players, students and workers, $25 \%$ are women and $75 \%$ are men, all between 20 and 29 years old and also with at least one year of experience in FPS Video Games.

The following variables were measured per player: number of eliminated enemies, player deaths, and the score generated individually and in group.

\section{B. Materials}

AssaultCube (AC) is an open source First Person Shooter (FPS) Collaborative Video Game that can be executed in desktop environments and has a server to be executed online. AC provides collaborative scenarios with tools that users can use to coordinate and communicate (e.g. private and group messaging, predetermined audio messaging). The chosen collaborative scenario was the mini-game Flag Capture. In this game, the members of a team must keep a yellow flag as long as possible (see Fig. 2). Each time a team member holds the flag for a 15-second period, he earns points for his team and for his personal account; therefore, teammates need to protect each other, and they must also destroy enemies that attempt to recover the flag. However, when the player carrying the flag is destroyed, the flag is available again so the enemy team can recover it to try to earn points.

For both experiments, $e_{1}$ and $e_{2}$, an instrument to measure user satisfaction was prepared (see Table I). The instrument consists of 12 questions that refer to 6 dimensions related to user satisfaction, such as (D1) Coordination (1-2), (D2) Communication (3-4), (D3) Cooperation (5-6), (D4) Entertaining (7-8), (D5) Ease (9-10) and (D6) Awareness (11-12). The possible answers to the questions go from 1 to 5 , where " 1 "

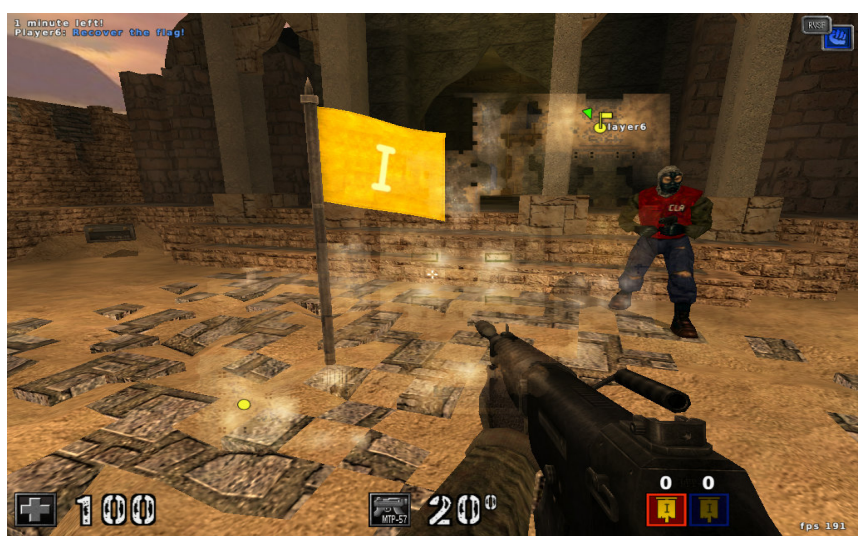

Figure 2. Video Game screen with location map and the flag.

stands for Strongly Disagree, "2" for Disagree, "3" Neither agree nor disagree, "4" Agree and "5" Strongly Agree. The consistency of this instrument was validate by applying a Cronbach Alpha coefficient to the answers obtained from the players in $e_{1}$. The Cronbach Alpha coefficient was applied to each dimension of the scale, and the results were as follows: $\mathrm{D} 1=0.7, \mathrm{D} 2=0.5, \mathrm{D} 3=0.6, \mathrm{D} 4=0.8, \mathrm{D} 5=0.5$ and $\mathrm{D} 6$ $=0.5$. As can be seen, values of dimensions D1, D3 and D4 are equal to or greater than 0.6 , therefore, the questions in these dimensions have a moderate/acceptable reliability. In the case of dimensions D2, D5 and D6, they did not reach a value of 0.6 or higher; however, the obtained data were not significant to discard these items. In addition, the average of all the dimensions was 0.6 , which is considered moderately acceptable. For future applications, it is expected to improve the items (D2, D5 and D6) and increase the sample size.

TABLE I. RELATION OF STATEMENTS IN THE SURVEY.

\begin{tabular}{|c|c|c|}
\hline No. & Dimention & Statement \\
\hline 1 & D1 & $\begin{array}{l}\text { Text messages offered by the game were helpful to organize } \\
\text { with your teammates. }\end{array}$ \\
\hline 2 & D1 & $\begin{array}{l}\text { Location map in the game helped you generate an estrategy } \\
\text { with your other teammates. }\end{array}$ \\
\hline 3 & D2 & $\begin{array}{l}\text { Audio messages predefined in the game were enough to } \\
\text { transmit your emotions in the game. }\end{array}$ \\
\hline 4 & D2 & $\begin{array}{l}\text { Text messages were useful for transmiting information to } \\
\text { your teammates during collaborative activity. }\end{array}$ \\
\hline 5 & D3 & $\begin{array}{l}\text { Location map of your teammates is useful to support the } \\
\text { group activity. }\end{array}$ \\
\hline 6 & D3 & $\begin{array}{l}\text { The video game offers suitable collaboration tools to help } \\
\text { your team. }\end{array}$ \\
\hline 7 & D4 & $\begin{array}{l}\text { The video game kept you entertained during the develop- } \\
\text { ment of the game. }\end{array}$ \\
\hline 8 & D4 & $\begin{array}{l}\text { Information (e.g. messages, alerts, etc.) shown on the game } \\
\text { interface possively affect your entertainment. }\end{array}$ \\
\hline 9 & D5 & $\begin{array}{l}\text { The video game is easy to use in order to collaborate with } \\
\text { your teammates. }\end{array}$ \\
\hline 10 & D5 & $\begin{array}{l}\text { The video game is easy to use in order to remove players } \\
\text { from the contrary team. }\end{array}$ \\
\hline 11 & D6 & $\begin{array}{l}\text { Knowing the location of your teammates on the map helped } \\
\text { your activity in the game. }\end{array}$ \\
\hline 12 & D6 & $\begin{array}{l}\text { Knowing the score of all the players positively changed } \\
\text { your behavior during the collaborative activity. }\end{array}$ \\
\hline
\end{tabular}




\begin{tabular}{|c|c|c|c|c|c|}
\hline \multicolumn{7}{|c|}{ Read Team } \\
\hline Player & Killed & Eliminated enemies & Messages & Flags & Score Total \\
\hline 1 & 13 & 28 & 0 & 0 & 193 \\
\hline 2 & 15 & 8 & 0 & 1 & 47 \\
\hline 3 & 5 & 7 & 0 & 0 & 54 \\
\hline 4 & 13 & 17 & 0 & 9 & 329 \\
\hline Total & $\mathbf{4 6}$ & $\mathbf{6 0}$ & $\mathbf{0}$ & $\mathbf{1 0}$ & $\mathbf{6 2 3}$ \\
\hline
\end{tabular}

\begin{tabular}{|c|c|c|c|c|c|}
\hline \multicolumn{5}{|c|}{ Blue Team } \\
\hline Player & Killed & Eliminated enemies & Messages & Flags & Score Total \\
\hline 1 & 5 & 0 & 0 & 0 & -20 \\
\hline 2 & 16 & 33 & 0 & 11 & 585 \\
\hline 3 & 10 & 2 & 0 & 0 & -30 \\
\hline 4 & 17 & 8 & 0 & 7 & 192 \\
\hline Total & $\mathbf{4 8}$ & $\mathbf{4 3}$ & $\mathbf{0}$ & $\mathbf{1 8}$ & $\mathbf{7 2 7}$ \\
\hline
\end{tabular}

Figure 3. Results of $e_{1}$.

\section{Procedure}

The procedure for observation and evaluation of the video game was the following:

1) The AC Video Game was installed on computers that were involved in the experimental study.

2) During 15 minutes, the participants were provided with a manual of the $\mathrm{AC}$ video game with the connection steps in order to connect to the server and operate successfully the means of collaboration.

3) During 10 minutes, a test mission (Team Deathmatch) was launched in order to familiarize participants with the game.

4) During 15 minutes, the activity "Team Keep the flag" $\left(a_{1}\right)$ was developed.

5) The questionary was applied to the participants.

\section{Results}

The results that were obtained during the game at $e_{1}$ can be seen in Fig. 3. In this case the winner was the blue team. The total score in the game is based on: i) accumulated points for every 15 seconds a player keeps the flag, ii) accumulated points for every eliminated enemy, iii) decreased points for every eliminated teammate and iv) decreased points for every dead player of the team.

In the $\mathrm{AC}$ video game experiment $1\left(e_{1}\right)$, the players did not use the communication tools (e.g. instant messenger, predefined audio messages). This occurred because they were in the same place; therefore, they communicated with their own voice and gestures. For example, some players expressed explicit phrases as: "Protect me, I have the flag!". So roles (e.g. guards, flag bearer) were created on-the-fly, and constantly changed during the game. Also, in many cases, group behavior depended on reactions of the bearer of the flag. For instance, if his teammates heard and saw that he was in a state of frustration, they protected him even when the bearer did not request help explicitly.

Fig. 4 presents the charts with the results obtained by the Likert instrument applied to players in $e_{1}$. The results related to dimension (D1) show an adverse opinion regarding the use of text messaging for coordination (item 1); however,

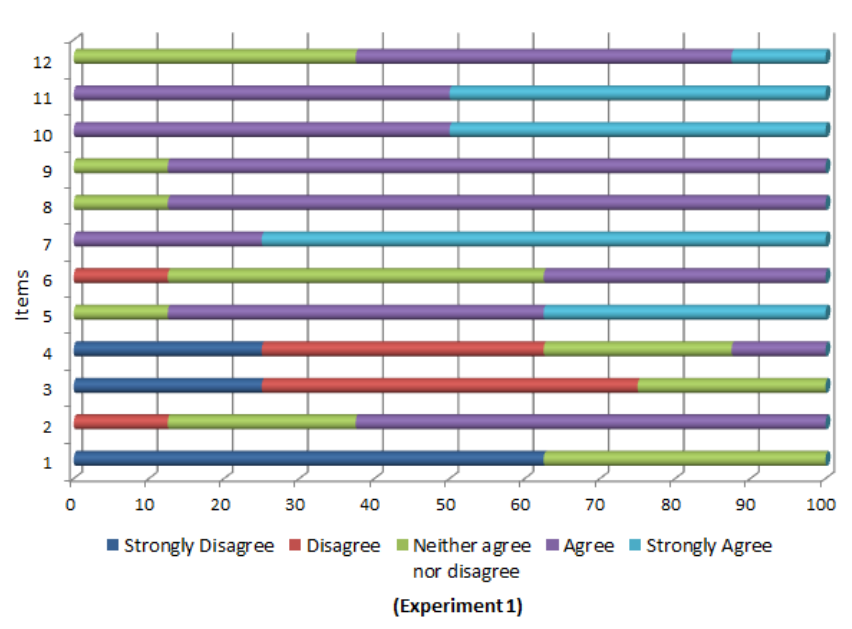

Figure 4. Summary of study results $e_{1}$.

this dimension is a positive attitude regarding the use of the map location (item 2). Dimension 2 (D2) shows the adverse opinion regarding for communication of players with AC tools. Dimension 3 (D3), related to cooperation, shows a positive trend in item 5, which is relates to location map, however, in item 6 , the trend of neutrality and dissatisfaction predominated. In dimension 4 (D4) and dimension 5 (D5) regarding the ease and entertaining, the trend is strongly in favor. Finally, in the dimension 6 (D6) of awareness, the trend is also accepted positively.

For the results of $e_{2}$, see Fig. 5. In this case, the winner was the red team; however, they had an unfavorable opinion regarding the collaboration mechanisms provided by AC. Most messages sent by the teams were not to coordinate and organize their actions, but to joke or threat their enemies. More points were generated in $e_{2}$ than in $e_{1}$; this can be explained if one considers that a more competitive environment is created when players are competing face-to-face, so eliminating enemies or capturing the flag is more difficult.

Fig. 6 presents the charts with the results obtained by the Likert instrument applied to players in $e_{2}$. As can be seen, D1 and D2 show an attitude of neutrality and dissatisfaction, in

\begin{tabular}{|c|c|c|c|c|c|}
\hline \multicolumn{6}{|c|}{ Read Team } \\
\hline Player & Killed & Eliminated enemies & Messages & Flags & Score Total \\
\hline 1 & 9 & 11 & 2 & 1 & 105 \\
\hline 2 & 10 & 11 & 3 & 2 & 142 \\
\hline 3 & 12 & 10 & 3 & 1 & 83 \\
\hline 4 & 10 & 34 & 10 & 8 & 558 \\
\hline Total & $\mathbf{4 1}$ & $\mathbf{6 6}$ & $\mathbf{1 8}$ & $\mathbf{1 2}$ & $\mathbf{8 8 8}$ \\
\hline
\end{tabular}

\begin{tabular}{|c|c|c|c|c|c|}
\hline \multicolumn{7}{|c|}{ Blue Team } \\
\hline Player & Killed & Eliminated enemies & Messages & Flags & Score Total \\
\hline 1 & 18 & 7 & 2 & 1 & 26 \\
\hline 2 & 0 & 21 & 0 & 4 & 258 \\
\hline 3 & 14 & 3 & 2 & 0 & -21 \\
\hline 4 & 15 & 8 & 15 & -1 & 0 \\
\hline Total & $\mathbf{4 7}$ & $\mathbf{3 9}$ & $\mathbf{1 9}$ & $\mathbf{4}$ & $\mathbf{2 6 3}$ \\
\hline
\end{tabular}

Figure 5. Results of $e_{2}$. 


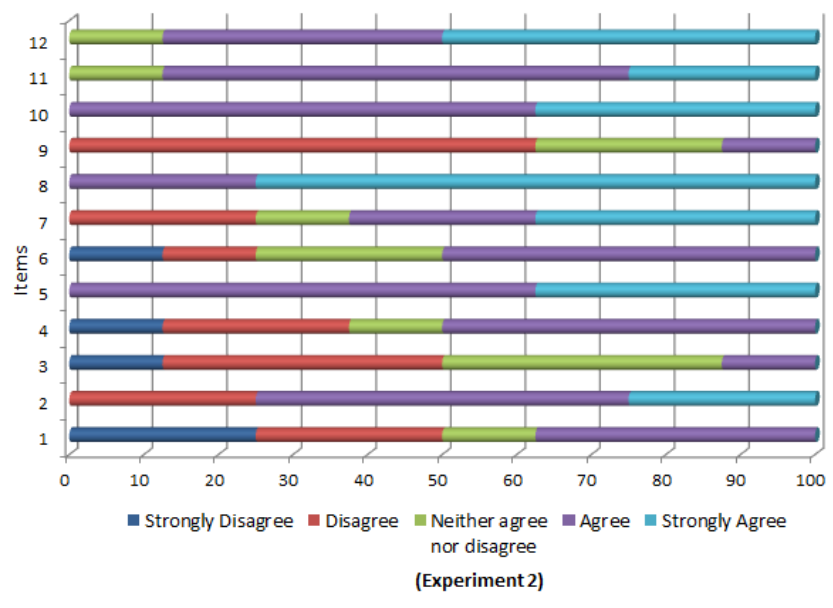

Figure 6. Summary of study results $e_{2}$.

D3 only the item 5 is predominant with a positive attitude, in item 6 showing a slight trend in favor. Finally, in D4, D5 and D6 also the point of view was in favor.

Let us note that the group behavior of helping the bearer of the flag without any explicit request was not present in experiment $2\left(e_{2}\right)$. This was because the tools currently offer by the videogame are not sufficient to transmit states of frustration, so the bearer needed to request help explicitly through text messages or predefined audio messages.

\section{E. Discussion}

The obtained results with the Likert instrument in $e_{1}$ and $e_{2}$ were opposite with respect to collaboration mechanisms (D1, D2, D3). This give us evidence that the traditional mechanisms offered in the FPS videogame are not sufficient and are not presented in the best way; therefore, it is interesting to propose better tools that include contextual information to make a more efficient collaboration. Finally, the evaluation also helped us identify social behaviors that could be studied in greater depth, for example, identification of moods, detection of group patterns, and recognition of social interactions, to name few.

\section{Context-Aware Model and Architecture}

Based on the findings of the exploratory study, this Section proposes a conceptual model and a generic architecture for CAGS.

\section{A. Model}

A conceptual model for Context-Aware Groupware Systems is presented in Fig. 7. For incorporating contextawareness into Groupware Systems, it is not only necessary to capture individual and social contextual data from different sources, but it is also important to consider a reasoning mechanism (logical or probabilistic) being able to infer highlevel contextual information, but also to help the users of Groupware Systems to make decisions based on the current context or to proactively take actions.

Table II shows the social context variables that we consider of interest for a Collaborative Video Game of type FPS. They
TABLE II. Social ConteXt Variables

\begin{tabular}{|c|c|c|c|}
\hline Category & Elements & Description & Examples \\
\hline \multirow{5}{*}{ Interactive } & Objects & $\begin{array}{l}\text { Artifacts instantiated } \\
\text { in the activity. }\end{array}$ & Messages, bonus refills. \\
\hline & Tasks & $\begin{array}{l}\text { Individual actions to } \\
\text { achieve goals through } \\
\text { the modification of } \\
\text { objects. }\end{array}$ & Capturing of flag. \\
\hline & Events & $\begin{array}{l}\text { Occurred events in } \\
\text { interactions. }\end{array}$ & Captured flag. \\
\hline & Users & $\begin{array}{l}\text { Entities belonging to } \\
\text { a community and } \\
\text { perform tasks. }\end{array}$ & Players Hugo and Luis. \\
\hline & Locations & $\begin{array}{l}\text { Location factor actors } \\
\text { to know where you are } \\
\text { physically or virtually } \\
\text { in a group. }\end{array}$ & $\begin{array}{l}\text { Luis is in the activity } \\
\text { of Team Keep the Flag } \\
\text { and Luis is at the } \\
\text { university. }\end{array}$ \\
\hline \multirow{6}{*}{ Cohesive } & Groups & $\begin{array}{l}\text { A collection of users } \\
\text { performing the activity. }\end{array}$ & Red team, blue team. \\
\hline & Roles & $\begin{array}{l}\text { Functions expected by } \\
\text { a user. }\end{array}$ & $\begin{array}{l}\text { Leader, protector, } \\
\text { bearer. }\end{array}$ \\
\hline & Goals & Community objectives. & $\begin{array}{l}\text { The team must retrieve } \\
\text { the flag. }\end{array}$ \\
\hline & Alliances & $\begin{array}{l}\text { Subset of users in the } \\
\text { group. }\end{array}$ & $\begin{array}{l}\text { Users with the aim of } \\
\text { achieving a record } \\
\text { score. }\end{array}$ \\
\hline & Activities & $\begin{array}{l}\text { Activities performed } \\
\text { by a group. }\end{array}$ & $\begin{array}{l}\text { Participate in the } \\
\text { battle to } \\
\text { keep the flag. }\end{array}$ \\
\hline & Rules & $\begin{array}{l}\text { Behaviors defined by } \\
\text { the group. }\end{array}$ & $\begin{array}{l}\text { If Luis has leader role } \\
\text { then he will receive all } \\
\text { messages from the team. }\end{array}$ \\
\hline \multirow{2}{*}{ Affective } & Moods & $\begin{array}{l}\text { Moods of users on a } \\
\text { Collaborative Activity. }\end{array}$ & Frustation, happiness. \\
\hline & Gestures & Gestures of the users. & $\begin{array}{l}\text { Laugh or cry of a } \\
\text { player. }\end{array}$ \\
\hline
\end{tabular}

are categorized according to three classes of social presence (interactive, cohesive, and affective), and for each of them a description and some examples are given.

To support proactive behavior of a CAGS, we propose social triggers. They are rules of the form Event-ConditionAction, where Event refers specifically to a social event of relevance in the system. For example, Luis $\left(p_{1}\right)$ can set a

\begin{tabular}{|c|}
\hline $\begin{array}{c}\text { Users } \\
\text { (Players) }\end{array}$ \\
\hline $\begin{array}{c}\text { Groupware System } \\
\text { (Videogames) }\end{array}$ \\
\hline $\begin{array}{c}\text { Computational Reasoning } \\
\text { (Pattern recognition, neuronal networks, ID3) }\end{array}$ \\
\hline $\begin{array}{c}\text { Contextual Information } \\
\text { (Individual and social: high or low level) }\end{array}$ \\
\hline Physical and Logical Data Sources \\
\hline
\end{tabular}

Figure 7. Conceptual model. 
trigger $\left(d_{1}\right)$ for the activity Teem keeps the flag $\left(a_{1}\right)$, so that when he takes the flag $\left(a c_{1}\right)$ some actions are automatically triggered, such as sending a predefined message to his closest teammate requesting for assistance $\left(a c_{2}\right)$, transmitting a predefined audio message to all team members to inform them the place to where he is going $\left(a c_{3}\right)$, or requesting information about where to find the closest place to recharge power $\left(a c_{4}\right)$. Social triggers speeds up the participation of a player in the game, and avoids possible distractions.

\section{B. Architecture}

Fig. 8 presents a context-aware architecture based on the proposed model. This architecture has four layers that are described below.

1) Groupware System Layer: This layer has direct communication with the users through the user interface and the means of collaboration provided by the Groupware System. The Groupware System send events occurred in the group to the Contextual Data Acquisition Layer.

2) Context-Usage Layer: This layer uses information provided by the Context-Management layer in order to infer and reason with social and individual context. Once this process is complete, the GS is adapted and manipulated depending on the result of the reasoning process.

3) Context-Management Layer: The primary functions of the Context-Management Layer are store, update and retrieve the context information acquired from the Contextual Data Acquisition Layer. Therefore, in this layer there is a data store that is accessed in order to process information.

4) Contextual Data Acquisition Layer: It is located at the lowest level; it acquires information directly from internal (wrt to the GS) and external data providers (such as web services,

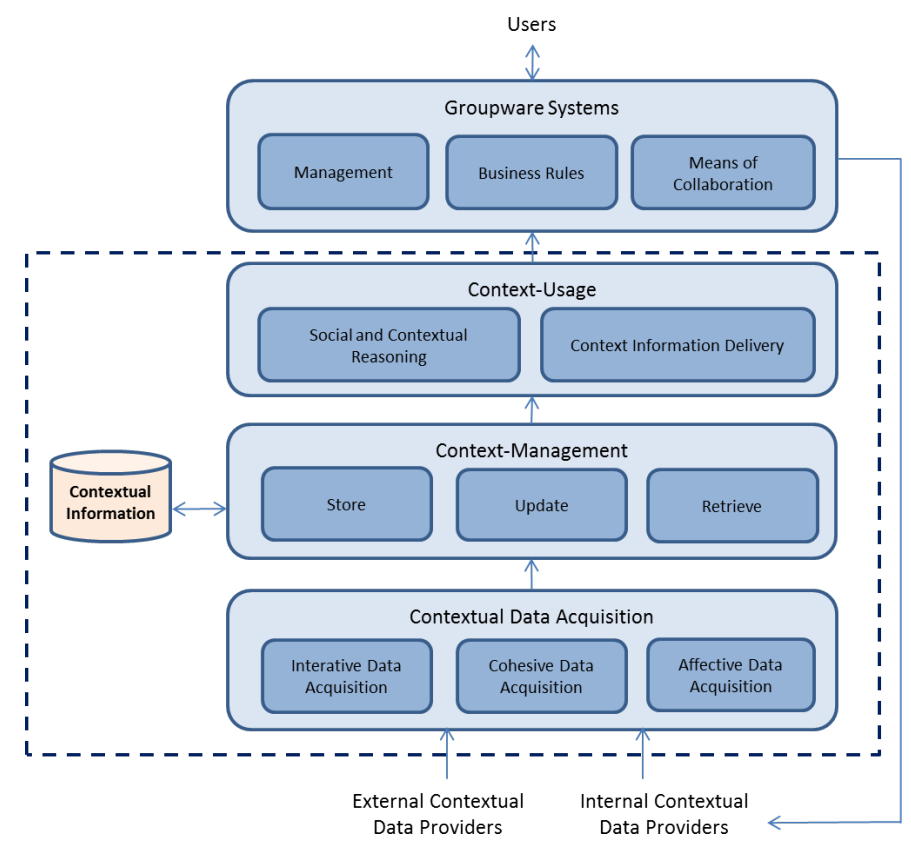

Figure 8. Conceptual Architecture. video capture from video cameras and audio capture from microphones).

\section{CONCLUSIONS AND FUture WORK}

This paper presented an exploratory study which had as objective to identify elements and conditions necessary to improve the traditional means of collaboration offered in CAGS, particularly in Video Games of type First-PersonShooter. Two experiments were executed, one where teams of gamers were playing at the same physical location, and other where they were geographically distributed. As result, it was found that nonverbal information (gestures, feelings, group behavior patterns) that is not captured nor processed is relevant for the collaborative activity. It was also found that gamers needed to deviate his/her attention of the game to send text messages, and that most of the time text messaging were not used to collaborate. Then, faster and more efficient collaboration tools are needed. With this evidence, a model and an architecture for CAGS that takes into account these findings were proposed.

Our future work includes modifying AssaultCube to integrate elements of context-awareness in order to support users to achieve their goals more efficiently. It is expected that the game will automatically provide appropriate means of collaboration (e.g. messages, maps) depending on the executed interaction (e.g. player captures the flag on the battlefield), without requiring the user to invoke such tools in an explicit manner. An experimental study will be designed and executed to compare both the regular version of the game and its context-aware version.

\section{ACKNOWLEDGMENT}

The authors thank the reviewers of this paper for their useful comments. The first author gratefully acknowledges to CONACYT for scholarship No. 350124 for graduate studies.

\section{REFERENCES}

[1] P. Dourish and V. Bellotti, "Awareness and coordination in shared workspaces," in Proc. ACM conference on Computer-supported cooperative work (CSCW '92), New York, NY, USA, 1992, pp. 107-114.

[2] F. Biocca, C. Harms, and J. K. Burgoon, "Toward a more robust theory and measure of social presence: review and suggested criteria," Presence: Teleoperators and Virtual Environments, vol. 12, no. 5, pp. 456-480, Oct. 2003.

[3] A. K. Dey, "Understanding and using context," Personal Ubiquitous Computing, vol. 5, no. 1, pp. 4-7, 2001.

[4] G. Chen and D. Kotz, "A Survey of Context-Aware Mobile Computing Research," Department of Computer Science, Darthmouth College, Technical Report TR2000-381, 2000.

[5] A. Kofod-Petersen and J. Cassens, "Using activity theory to model context awareness," in Modeling and Retrieval of Context: Second International Workshop (MRC'05), ser. Lecture Notes in Computer Science, vol. 3946. Springer-Verlag, 2006, pp. 1-17.

[6] M. Kaenampornpan and E. O'Neill, "An integrated context model: Bringing activity to context," in Proc. of the Workshop On Advanced Context Modelling, Reasoning and Management (UBICOMP'04), Nottingham, UK, 2004.

[7] L. X. Hung, S. Lee, Y.-K. Lee, and H. Lee, "Activity-based access control model to hospital information," in Proc. IEEE International Conference on Embedded and Real-Time Computing Systems and Applications (RTCSA'07), Daegu, aug 2007, pp. 488-496. 
[8] J. E. Bardram and H. B. Christensen, "Pervasive computing support for hospitals: An overview of the activity-based computing project," Pervasive Computing, IEEE, vol. 6, no. 1, pp. 44-51, Jan. 2007.

[9] Y. Mowafi and D. Zhang, "A user-centered approach to contextawareness in mobile computing," in Proc. of the 2007 Fourth Annual International Conference on Mobile and Ubiquitous Systems: Networking \&Services (MobiQuitous'07). Washington, DC, USA: IEEE Computer Society, 2007, pp. 1-3.

[10] R. Hervás, J. Bravo, and J. Fontecha, "A context model based on ontological languages: A proposal for information visualization," Universal Computer Science, vol. 16, no. 12, pp. 1539-1555, jun 2010.

[11] W. Romsaiyud and W. Premchaiswadi, "Soa context-aware mobile data model for emergency situation," in Proc. IEEE 8th International Conference on ICT and Knowledge Engineering'10, Bangkok, nov 2010, pp. 93-97.

[12] R. Messeguer, Medina and J.Fave, "Supporting context-aware collaborative learning through automatic group formation," in Proc. 4th International Symposium on Ubiquitous Computing and Ambient Intelligence (UCAmI'10), Valencia, España, sep 2010.

[13] E. Benítez, C. Mezura, and L. Montané, "Context-aware mobile collaborative systems: Conceptual modeling and case study," Sensors, vol. 12, no. 10, pp. 13 491-13 507, oct 2012.

[14] H. A. Duran-Limon, G. S. Blair, A. Friday, P. Grace, G. Samartzidis, T. Sivaharan, and M. Wu, "Context-aware middleware for pervasive and ad hoc environments," Tech. Rep., 2003.

[15] R. Mayrhofer, "An architecture for context prediction," in Advances in Pervasive Computing. Austrian Computer Society (OCG), apr 2004, vol. 176, pp. 65-72, part of the Second International Conference on Pervasive Computing (PERVASIVE'04).

[16] A. Olivares, S. Mendoza, and A. de Luca, "An architecture to support context of use in groupware systems," in Proc. 8th International Conference on Electrical Engineering Computing Science and Automatic Control (CCE'11), Merida City, oct 2011, pp. 1-6.

[17] J. Favela, M. Alba, and M. Rodríguez, "Autonomous agents for ubiquitous collaborative environments," in Proc. of the Second Mexican International Conference on Artificial Intelligence: Advances in Artificial Intelligence (MICAI'02), ser. Lecture Notes in Computer Science, C. Coello Coello, A. de Albornoz, L. Sucar, and O. Battistutti, Eds. Springer Berlin-Heidelberg, 2002, vol. 2313, pp. 351-360.

[18] F. Siegemund, "A context-aware communication platform for smart objects," in Proc. Second International Conference on Pervasive Computing (PERVASIVE'04), ser. Lecture Notes in Computer Science, A. Ferscha and F. Mattern, Eds. Vienna, Austria: Springer-Verlag Berlin Heidelberg, 2004, vol. 3001, pp. 69-86.

[19] S. S. Yau and F. Karim, "An adaptive middleware for context-sensitive communications for real-time applications in ubiquitous computing environments," Real-Time Systems, vol. 26, pp. 29-61, jan 2004.

[20] T. Gu, H. K. Pung, and D. Q. Zhang, "A service-oriented middleware for building context-aware services," Network and Computer Applications, vol. 28, no. 1, pp. 1-18, jan 2005.

[21] J. Schroyen, K. Luyten, K. Gabriels, K. Robert, D. Teunkens, K. Coninx, E. Flerackers, and E. Manshoven, "The design of context-specific educational mobile games," in Proc. Workshop on Museums and the Web: The International Conference for Culture and Heritage Online, J. Trant and D. Bearman, Eds. Indianapolis, USA: Toronto: Archives and Museum Informatics, apr 2009.

[22] C. Lu, M. Chang, Kinshuk, E. Huang, and U. of Context-Aware Mobile Educational Game, "Usability of context-aware mobile educational game," Knowledge Management \& E-Learning, vol. 3, 2011.

[23] D. Kulkarni, T. Ahmed, and A. Tripathi, "A generative programming framework for context-aware cscw applications," ACM Transactions on Software Engineering and Methodology, vol. 21, no. 2, pp. 11:1-11:35, Mar. 2012.

[24] B. P. László Kovács, Péter Mátételki, "Service-oriented context-aware framework," in Proc. Fourth European Young Researchers Workshop on Service Oriented Computing (YR-SOC'09), Pisa, Italy, jun 2009.

[25] N. Nova, "Awareness tools: lessons from quake-like," in Proc. of Playing with the Future Conference, apr 2001.

[26] N. Nova, T. Wehrle, J. Goslin, Y. Bourquin, and P. Dillenbourg,
"Collaboration in a multi-user game: impacts of an awareness tool on mutual modeling," Multimedia Tools Applications, vol. 32, no. 2, pp. 161-183, Feb. 2007.

[27] K. Diamantaki, C. Rizopoulos, D. Charitos, and N. Tsianos, "Theoretical and methodological implications of designing and implementing multiuser location-based games," Personal and Ubiquitous Computing, vol. 15, no. 1, pp. 37-49, jan 2011.

[28] N. P. Zea, J. L. G. Sanchez, and F. L. Gutierrez, "Collaborative learning by means of video games: An entertainment system in the learning processes," in Proc. of the 2009 Ninth IEEE International Conference on Advanced Learning Technologies (ICALT'09). Washington, DC, USA: IEEE Computer Society, 2009, pp. 215-217.

[29] J.-C. Marty and T. Carron, "Observation of collaborative activities in a game-based learning platform," IEEE Transactions on Learning Technologies, vol. 4, no. 1, pp. 98-110, Jan. 2011. 